Jurnal Kebidanan 09 (01) 1 - 101

Jurnal Kebidanan

http : //www. journal.stikeseub.ac.id

\title{
EFEKTIFITAS PEMBELAJARAN FIELDTRIEP TERHADAP PENCAPAIAN KOMPETENSI DALAM DETEKSI DINI PERKEMBANGAN ANAK
}

\author{
Novita Nurhidayati ${ }^{1)}$, Triani Yuliastanti $^{2)}$ \\ 1)2) 3) Prodi DIII Kebidanan, Stikes Estu Utomo Boyolali \\ E-mail: novita1259@gmail.com
}

\begin{abstract}
ABSTRAK
Latar belakang : Perkembangan anak sangat menentukan kualitas Sumber Daya Manusia (SDM) pada tahap-tahap selanjutnya. Maka dari itu seorang anak diharapkan dapat mencapai tahap perkembangan sesuai dengan kurva perkembangan. Perkembangan seorang anak dipengaruhi oleh beberapa faktor yaitu genelik dan lingkungan. Faktor lingkungan antara lain gizi, lingkungan dan stimulasi perkembangan. Salah satu kompetensi yang harus dikuasai mahasiswa D III Kebidanan adalah dapat melakukan deteksi dini perkembangan anak, salah satunya menggunakan lembar KPSP, yang termuat dalam mata kuliah Asuhan Neonatus, Bayi, dan Balita. Tujuan: Untuk mengetahui efektifitas pembelajaran filedtrip terhadap pencapaian kompetensi dalam deteksi dini perkembangan anak. Metode Penelitian: Menggunakan metode deskriptif observasioanal dengan one group pre dan post test design, serta pendekatan waktu cross sectional. Populasi dalam penelitian ini adalah semua mahasiswa semester 3 Akademi Kebidanan Estu Utomo Boyolali Tahun Akademik 2013/2014. dengan teknik total sampling, sejumlah 92 mahasiswa kemudian analisa data dengan Paired samples T-test. Hasil Penelitian terdapat 82 mahasiswa yang tidak kompeten dan 10 mahasiswa yang kompeten dalam melakukan deteksi dini perkembangan anak sebelum dilakukan metode pembelajaran fieldtriep. Setelah dilakukan pembelajaran dengan metode fieltriep terdapat 4 mahasiswa yang belum kompeten dan 84 mahasiswa yang kompeten. Hasil analisa data dengan SPSS 16.00 didapatkan nilai Sig (2-tailed) $=0,000$, pada taraf signifikansi $95 \%$ diperoleh $t$ hitung $(20,830)>t$ tabel $(1,896)$. Simpulan Terdapat pengaruh yang signifikan pada penggunaan metode pembelajaran fieldtriep terhadap pencapaian kompetensi mahasiswa dalam melakukan deteksi dini perkembangan anak.
\end{abstract}

Kata kunci : fieldtriep, KPSP

\section{EFFECTIVENESS FIELD TRIP LEARNING TO THE ACHIEVEMENT OF COMPETENCY IN EARLY DETECTION OF CHILDREN DEVELOPMENT}

\begin{abstract}
Background: The development of the child will determine the quality of Human Resources (HR) at later stages. Thus the child is expected to reach the stage of development in accordance with the development curve. A child's development is influenced by several factors, namely genelik and environment. Environmental factors such as nutrition, environmental and developmental stimulation. One of the competencies that must be mastered DIII Midwifery students are able to make early detection of child development, one of which uses KPSP sheet, which contained the subjects Care Neonates, Infants, and Toddlers. Purpose: To determine the effectiveness of learning filedtrip to the achievement of competence in the early detection of child development. Methods: Using a descriptive method observasioanal with one group pre and post test design, as well as the cross sectional approach. The population in this study were all students of the 3rd semester Midwifery Academy Estu Utomo Boyolali Academic Year 2013/2014. with a total sampling techniques, a number of 92 students then analyze the data with paired samples T-test. Results are 82 students who are incompetent and 10 students who are competent in the early detection of child development before learning methods fieldtriep. After learning the method fieltriep there are 4 students who have not qualified and competent students 84 . The results of the data analysis with SPSS 16:00 got the Sig (2-tailed) $=0.000$, at a significance level of $95 \%$ was obtained $t(20,830)>t$ table (1.896). Conclusions There is a significant influence on the use of learning methods fieldtriep to the achievement of student competence in the early detection of child development
\end{abstract}

Keywords: fieldtriep, KPSP 
PENDAHULUAN

Evaluasi merupakan proses sistematis untuk membuat keputusan terkait sejauh mana tujuan pembelajaran berhasil dicapai oleh mahasiswa (Hamalik, 2008). Dalam menentukan evaluasi pembelajaran, dosen sebaiknya mempertimbangkan berbagai aspek yang ada pada mahasiswa. Contohnya adalah gaya belajar yang berbeda-beda pada mahasiswa, ada yang nyaman dalam memberikan presentasi maupun berdiskusi, ada pula yang lebih optimal menyerap pelajaran dengan berpikir reflektif serta menuangkan pikiran secara tertulis, tetapi terkadang pemberian tugas memberikan andil dalam pencapaian kompetensi mahasiswa.

Pada hakikatnya evaluasi merupakan laporan akhir dari proses pembelajaran, khususnya laporan mengenai kemajuan dan prestasi belajar siswa. Oleh karena itu, dapat dikatakan bahwa evaluasi merupakan pertanggungjawaban guru dalam pelaksanaan proses pembelajaran. Evaluasi merupakan bagian penting dalam suatu sistem instruksional. Sebagaimana pendapat yang dikemukakan oleh Hamalik (2001).

Seorang dosen sebaiknya mempertimbangkan komposisi dan proporsi penilaian sedemikian rupa. Dengan demikian, semua mahasiswa memiliki kesempatan yang sebesar- besarnya untuk unjuk performa. Di Akademi Kebidanan Estu Utomo Boyolali setiap akhir semester mengadakan evaluasi secara teori maupun skill, salah satunya adalah pada mata kuliah Asuhan Neonatus, Bayi, dan Balita. Kompetensi yang harus dikuasai mahasiswa salah satunya adalah melakukan deteksi dini tehadap pertumbuhan dan perkembangan anak dengan menggunakan KPSP.

Periode terpenting dalam perkembangan anak adalah pada saat anak berusia balita. Dalam masa ini peran orang tua akan sangat berpengaruh terhadap perkembangan anak. Pada usia ini seorang anak masih membutuhkan orang tua sebagai pendamping, peran orang tua adalah sebagai penolong baik berupa fisik maupun psikologi. Perkembanagan yang terjadi pada masa ini antara lain kemampuan berbahasa, kreativitas, kesadaran sosial, emosional, dan intelegensia yang merupakan landasan perkembangan berikutnya (Langgulung, 2008).

Perkembangan anak adalah segala perubahan yang terjadi pada anak yang meliputi seluruh perubahan dalam perkembangan anak yaitu perkembangan fisik, kognitif, emosi, maupun psikososial yang terjadi dalam usia anak. Perkembangan ini sangat menentukan kualitas Sumber Daya Manusia (SDM) pada tahap-tahap selanjutnya. Maka dari 
itu seorang anak diharapkan dapat mencapai tahap perkembangan sesuai dengan kurva perkembangan (Endah, 2008).

Pola dan karakteristik perkembangan dapat diramalkan, baik untuk pola perkembangan mental maupun perkembangan fisik. Artinya apabila anak pada usia awal dalam kehidupannya mempunyai ciri-ciri perkembangan fisik dan mental yang tidak normal, maka dapat diramalkan bahwa kondisi perkembangan anak pada usia remaja atau dewasa akan mengalami pula abnormalitas (Fitri, 2006).

Pemerintah telah melakukan berbagai upaya, salah satunya adalah pelaksanaan program SDIDTK. Termasuk didalamnya adalah penilaian perkembangan anak dengan menggunakan KPSP. Bidan sebagai salah satu tenaga medis yang bertanggungjawab dalam penilaian perkembangan anak karena merupakan salah satu kegiatan yang harus dilaksanakan di posyandu. Sehingga bidan di tuntut untuk menguasai salah satu instrumen untuk penilaian perkembangan anak yaitu KPSP.

Oleh karena itu peneliti ingin mengetahui tingkat kompetensi yang dicapai mahasiswa dengan membandingkan hasil pembelajaran dengan metode ceramah dengan mengajak mahasiswa terjun langsung ke lapangan mencari kasus secara fieldtriep. Sehingga luaran yang diharapkan nanti adalah sebuah jurnal dan buku teks tentang keefektifan pembelaran dengan metode fieldtrip.

\section{METODE}

Jenis penelitian ini adalah deskriptif kuantitatif. Pada penelitian ini, pendekatan yang digunakan adalah cross sectional dengan rancangan one group pre dan post test design. Tempat penelitian di Akademi Kebidanan Estu Utomo Boyolali. Waktu penelitian pada bulan Desember 2013 sampai dengan bulan Agustus 2014. Populasi penelitian adalah seluruh mahasiswa semester 3 Akademi Kebidanan Estu Utomo Boyolali tahun Akademik 2013/2014. Sampel diambil secara total sampling sejumlah 92 mahasiswa. Variabe bebas adalah Efektifitas pembelajaran fieldtriep dan variabel terikat adalah kompetensi mahasiswa dalam melakukan deteksi dini perkembangan anak.

Pengumpulan data menggunakan data primer, yaitu lembar kerja mahasiswa dalam melakukan deteksi dini perkembangan anak. Sebelum dilakukan pembelajaran fiedtriep mahasiswa diberikan soal untuk menilai perkembangan anak. Setelah itu mahasiswa diajak ke posyandu dan diberikan materi tentang penilaian perkembangan nak menggunakan KPSP. 
Setelah itu diberi penugasan untuk mengambil satu balita untuk dinilai perkembangannya menggunakan KPSP.

Kemudian nilai mahasiswa akan dibandingkan antara sebelum dengan setelah dilakukan pembelajaran fieldtriep. Hipotesis dalam penelitian ini adalah "ada pengaruh pada metode pembelajaran fildtriep terhadap kompetensi mahasiswa dalam melakukan deteksi dini perkembangan anak. Data yang diperoleh dianalisa secara statistik dengan uji Paired Samples T-test.

\section{HASIL DAN PEMBAHASAN}

\section{Analisa Univariat}

a. Kompetensi mahasiswa dalam deteksi dini perkembangan anak sebelum dilakukan metode pembelajaran fieldtriep

Tabel 1. Distribusi frekuensi responden kompetensi mahasiswa sebelum dilakukan metode pembelajaran fiedtriep Tahun 2014

\begin{tabular}{lcc}
\hline $\begin{array}{l}\text { Kompetensi } \\
\text { Mahasiswa }\end{array}$ & Frekuensi & $\begin{array}{c}\text { Persentase } \\
(\%)\end{array}$ \\
\hline $\begin{array}{l}\text { Kompeten } \\
\text { Tidak } \\
\text { kompeten }\end{array}$ & 10 & 10.87 \\
\hline \multicolumn{1}{c}{ Total } & 82 & 89.13 \\
\hline
\end{tabular}

Sumber : Data primer diolah
Berdasarkan dari data tabel 1 diatas menunjukkan bahwa dari 92 mahasiswa sebagian besar tidak kompeten dalam melakukan deteksi dini perkembangan anak setelah dilakukan pembelajaran dengan metode konvensional, yaitu 82 mahasiswa.

b. Kompetensi mahasiswa dalam deteksi dini perkembangan anak setelah dilakukan metode pembelajaran fieldtriep

Tabel 2. Distribusi frekuensi kompetensi mahasiswa setelah dilakukan metode pembelajaran fieldtriep Tahun 2014

\begin{tabular}{ccc}
\hline $\begin{array}{c}\text { Kompetensi } \\
\text { Mahasiswa }\end{array}$ & Frekuensi & $\begin{array}{c}\text { Persentase } \\
(\%)\end{array}$ \\
\hline $\begin{array}{c}\text { Kompeten } \\
\text { Tidak } \\
\text { kompeten }\end{array}$ & 88 & 95.65 \\
\hline Total & 92 & 4.35 \\
\hline
\end{tabular}

Sumber : Data primer diolah

$$
\text { Berdasarkan dari data }
$$

tabel 2 diatas menunjukkan bahwa dari 92 mahasiswa sebagian besar kompeten dalam melakukan deteksi dini perkembangan anak setelah dilakukan pembelajaran dengan metode fieldtriep, yaitu 88 mahasiswa. 


\section{Analisa Bivariat}

Paired Samples Test

\begin{tabular}{|c|c|c|c|c|c|c|c|c|}
\hline & \multicolumn{5}{|c|}{ Paired Differences } & \multirow[b]{3}{*}{$\mathrm{T}$} & \multirow[b]{3}{*}{ df } & \multirow[b]{3}{*}{ Sig. (2-tailed) } \\
\hline & \multirow[b]{2}{*}{ Mean } & \multirow{2}{*}{$\begin{array}{c}\text { Std. } \\
\text { Deviation }\end{array}$} & \multirow{2}{*}{$\begin{array}{c}\text { Std. Error } \\
\text { Mean }\end{array}$} & \multicolumn{2}{|c|}{$\begin{array}{l}95 \% \text { Confidence } \\
\text { Interval of the } \\
\text { Difference }\end{array}$} & & & \\
\hline & & & & Lower & Upper & & & \\
\hline $\begin{array}{cc}\text { Pair 1 } & \text { Konv } \\
& \text { ensio } \\
& \text { nal - } \\
& \text { Fieldt } \\
& \text { riep }\end{array}$ & -.84783 & .39040 & .04070 & -.92868 & -.76698 & -20.830 & 91 & .000 \\
\hline
\end{tabular}

Setelah di analisa secara statistik dengan menggunakan Paired Sampes T-test diadapatkan Sig. $(2$-tailed $)=0.000$, pada taraf signifikansi $\alpha=5 \%$ didapatkan dan t hitung $(20,830)>\mathrm{t}$ tabel $(1,896)$. Sehingga dapat disimpulakan terdapat pengaruh antara sebelum dan sesudah penggunaan metode pembelajaran fiedtrip terhdapa kopetensi mahasiswa dalam melakukan deteksi dini perkembangan anak.

\section{PEMBAHASAN}

Berdasarkan hasil penelitian menunjukkan bahwa dari 92 mahasiswa sebagian besar tidak kompeten dalam melakukan deteksi dini perkembangan anak setelah dilakukan pembelajaran dengan metode konvensional, yaitu 82 mahasiswa. Berdasarkan dari data tabel 2 diatas menunjukkan bahwa dari 92 mahasiswa sebagian besar kompeten dalam melakukan deteksi dini perkembangan anak setelah dilakukan pembelajaran dengan metode fieldtriep, yaitu 88 mahasiswa.
Berdasarkan hasil penelitian di dapatkan kompetensi mahasiswa dalam melakukan deteksi dini perkembangan anak sebelum dilakukan metode pembelajaran fieldtriep terdapat $89,13 \%$ mahasiswa yang tidak kompeten. Kemudian setelah dilakukan metode pembelajaran filedtriep didapatkan mahasiswa yang tidak kompeten tinggal 4,35\% . Hal ini menunjukkan perbedaan hasil yang signifikan antara sebelum dilakukan pembelajaran fieldtriep dengan sesudah dilakukan, dibuktikan terdapat 95,65\% mahasiswa kompeten dalam melakukan deteksi dini perkembangan anak.

Sesuai dengan teori dari Kartika, L (2008) menyatakan proses belajar mengajar berhasil dengan baik jika siswa berinteraksi dengan semua alat inderanya. Dosen berupaya menampilkan rangsangan (stimulus) yang dapat diproses dengan berbagai indera. Pada pelaksanaan metode pembelajaran fieldtriep dilakukan di posyandu, dimana mahasiswa dapat 
menngunakan semua alat inderanya karena langsung mendapatkan kasus nyata yaitu balita yang akan dinilai perkembangannya, sehingga mahasiswa dapat mempraktekkan langsung apa yang sudah di berikan oleh dosen.

Setelah dilakukan analisa data dengan Paired- Samples $t$ Test diadapatkan Sig. (2-tailed) $=0.000$ dan pada pada taraf signifikansi $\alpha=5 \%$ didapatkan dan $\mathrm{t}$ hitung $(20,830)>\mathrm{t}$ tabel $(1,896)$ sehingga dapat di simpulkan bahwa motode pembelajaran fieldtriep efektif untuk mencapai kompetensi mahasiswa dam melakukan deteksi dini perkembangan anak.

Prestasi belajar yang dalam hal ini adalah kompetensi mahasiswa dipengaruhi bagaimana mahasiswa mempelajari materi dengan menyenangkan serta bagaimana mahasiswa dan dosen berinteraksi dalam proses pembelajaran. Diharapkan dengan adanya interaksi tersebut maka hasil belajar mahasiswa dapat dicapai secara maksimal. Hal tersebut sesuai dengan pendapat Sardiman AM (2005) yang menyatakan bahwa terdapat salah satu bentuk motivasi adalah motivasi ekstrinsik, yaitu hal atau keadaan yang datang dari luar individu siswa, yang mendorongnya untuk melakukan kegiatan belajar. Jadi motivasi mahasiswa dapat ditimbulkan oleh dosen dengan berbagai cara, misalnya metode yang variatif, sehingga mahasiswa senang untuk belajar.

Hal tersebut dapat di temukan pada saat pembelajaran fiedtriep, karena pada saat pembelajaran dilakukan diluar ruangan kelas, dalam hal ini di posyandu, mahasiswa termotivasi untuk lebih percaya diri karena masyarakat menganggap mahasiswa sebagai tenaga medis yang dapat memberikan pelayanan di posyandu termasuk dalam melakukan deteksi dini perkembangan anak. Metode filedtrip disebut juga metode karya wisata mempunyai beberapa kelebihan, antara lain : memiliki prinsip pengajaran modern yang memanfaatkan lingkungan nyata dalam pengajaran, membuat apa yang dipelajari lebih relevan dengan kenyataan dan kebutuhan masyarakat, dapat merangsang kreativitas mahasiswa, dan informasi sebagai bahan mata kuliah lebih luas dan aktual. (Syaiful Bahri Djamarah, 2006: 94).

Walaupun masih didapatkan mahasiswa yang belum kompeten yaitu sebesar 4,35\%, kemungkinan faktorfaktor lain yang mempengaruhi kompetensi mahasiswa, misalnya minat, suasana kelas, emosi atau kesehatan mahasiswa pada waktu mengikuti fieldtriep. Mahasiswa yang memiliki motivasi yang kuat dalam mengikuti proses pembelajaran terlihat penuh semangat, antusias, memiliki rasa ingin tahu yang tinggi, aktif dalam 
pembelajaran, rajin dalam mengerjakan tugas-tugas yang diberikan dosen,

sehingga mereka memiliki daya tahan yang cukup lama dalam menyelesaikan pembelajaran.

Dengan adanya hasil penelitian di atas dapat disimpulkan metode pembelajaran fiedtrief sangat efektif dala mencapai kompetensi mahasiswa khususnya dalam melakukan deteksi dini perkembangan anak.

\section{PENUTUP}

Setelah dilakukan penelitian mengenai Efektifitas Pembelajaran Fieldtriep terhadap Pencapaian Kompetensi dalam Deteksi Dini Perkembangan Anak, dapat disimpulkan sebagai berikut : Terdapat 82 mahasiswa yang tidak kompeten dan 10 mahasiswa yang kompeten dalam deteksi dini perkembangan anak dengan metode pembelajaran konvensional. Terdapat 88 mahasiswa yang tidak kompeten dan 4 mahasiswa yang kompeten dalam deteksi dini perkembangan anak dengan metode pembelajaran konvensional. Terdapat perbedaan kompetensi yang di capai mahasiswa dalam deteksi dini perkembangan anak antara yang di beri pembelajaran dengan metode konvensional dengan metode fieldtriep

Sehingga diharapkan institusi lebih meningkatkan kerjasama dengan pihak lahan utuk memperluas lahan untuk pembelajaran fieltriep, Metode pebelajaran harus disesuaikan dengan target kompetensi yang akan dicapai mahasiswa, serta Setiap dosen sebaiknya menggunakan metode pembelajaran yang bervariasi.

\section{DAFTAR PUSTAKA}

Alwi, Muliaji. 2011. Kebutuhan dasar anak. from: www.InfoBalita.com. Diakses tanggal: 1 Desember 2013

Arikunto, Suharsimi, 2010. Prosedur Penelitian Suatu Pendekatan Praktek. Jakarta : Rineka Cipta.

DepKes RI. 2005. Buku pedoman Stimulasi Deteksi dan Intervensi Dini Tumbuh Kembang Anak. Jakarta: DepKes RI

Hurlock, EB. 2005.Perkembangan Anak, Jilid I. Jakarta : Erlangga.

Kemendiknas. 2012. Pendidikan Anak Usia Dini. from: www.Kemendiknas.com. Diakses tanggal: 5 Desember 2013

Noorlaila. 2009. Pendidikan Anak Usia Dinifrom: www. Kemendiknas.com. . Diakses tanggal: 1 Juli 2014

Santi. 2009. Pendidikan Anak. from: www.TanyaDokter.com. Diakses tanggal: 5 Juli 20114 